\title{
ISOLATION OF A COMPOUND FROM THE BULBS OF ELEUTHERINE BULBOSA (MILLER) URBAN (IRIDACEAE)
}

\author{
RANI VS* \\ Department of Botany, University of Kerala, Kariyavattom Campus, Thiruvananthapuram, Kerala, India. Email: ranisankar28@gmail.com. \\ Received: 01 February 2018, Revised and Accepted: 26 March 2018
}

\begin{abstract}
Objective: The present study is concerned with the detection, isolation, identification, and structural elucidation of the bioactive phytochemical from the bulbs of Eleutherine bulbosa.

Methods: Ethyl acetate is the solvent used in Soxhlet extraction. Column chromatography and thin layer chromatography is employed in the isolation procedure. Identification and structural elucidation of the bioactive compound is determined using ultraviolet-visible (UV-vis), Fourier transform-infrared (FTIR) spectroscopy, liquid chromatography-mass spectrometry (LCMS-MS), and ${ }^{1} \mathrm{H}$ nuclear magnetic resonance ( ${ }^{1} \mathrm{HNMR}$ ) spectroscopy.
\end{abstract}

Results: A compound was isolated from the bulbs of E. bulbosa by solvent extraction and chromatography. UV-vis, FTIR spectroscopy, LCMS-MS, and ${ }^{1}$ HNMR studies showed that the isolated compound was bis (2-6,7-diamino-5,8-dioxo naphthalene-1yl) propanal.

Conclusion: An yellowish-brown crystalline needle-shaped compound was isolated from the bulbs of E. bulbosa and characterized chemically. Spectroscopic analysis identified the compound as bis (2-6,7-diamino-5,8-dioxo naphthalene-1yl) propanal. Mass of the compound is $\mathrm{m} / \mathrm{z} 244$ $(\mathrm{MH}+=245)$.

Keywords: Eleutherine bulbosa, Chromatographic techniques, Naphthoquinone derivative, spectroscopy.

(C) 2018 The Authors. Published by Innovare Academic Sciences Pvt Ltd. This is an open access article under the CC BY license (http://creativecommons. org/licenses/by/4. 0/) DOI: http://dx.doi.org/10.22159/ajpcr.2018.v11i6.25059

\section{INTRODUCTION}

Eleutherine bulbosa (Miller) Urban belongs to the tribe Tigrideae of the family Iridaceae. It is an herbaceous seasonal perennial with plicate leaves, white stellate flowers, and fleshy bulbs covered with red tunics. Although the plant originated in the tropical American countries, it has got naturalized in several parts of the world such as South Africa, China, India, and the Philippines [1]. E. bulbosa is an important element of American Indian pharmacopeia and is often cultivated in gardens maintained by Indian tribes [2].

In the Indian subcontinent, E. bulbosa has been reported from the states of Odisha, Kerala, and Tamil Nadu [3,4]. It is interesting to note that even though E. bulbosa is an exotic ornamental, the local medical men in Kerala have identified its medicinal properties and the bulb is being used as a cure for various ailments. The plant is known by the local names "Vizhanarayani" or "Neerootikizhangu." The bulbs are used as an antidote to poisonous insect bites [4] and in regulating blood pressure [5]. The local tribals in Odisha use the bulb to treat diarrhea [3]. The antibacterial and cytotoxic potential of the crude ethyl acetate extract of the bulbs has been reported [6,7]. The bioactive compounds in the bulb extracts of $E$. bulbosa are inferred to be naphthoquinones, and a few of their derivatives have been isolated [8-12]. Since the bulbs of E. bulbosa are being used extensively among traditional medicinal practitioners, are rich in bioactive phytoconstituents, and are known to exhibit biological activities, the plant appears to be a good candidate for phytochemical study.

The present report is concerned with the detection, isolation, identification, and structural elucidation of the bioactive phytochemical from the bulbs of E. bulbosa.

\section{MATERIALS AND METHODS}

Bulbs of E. bulbosa (Figs. 1 and 2) were collected from different parts of Kerala and authenticated by the curator, Department of Botany,
University of Kerala, Kariavattom, Thiruvananthapuram. A voucher specimen (KUBH 5802) has been deposited in the department herbarium.

The bulbs of the plant were collected, cleaned, shade dried and powdered and stored in properly labeled, and air-tight bottles for further experiments.

\section{Extraction procedure and isolation \\ Extraction}

About $600 \mathrm{~g}$ of the bulb powder was extracted with 51 ethyl acetate for $10 \mathrm{~h}$ at $77^{\circ} \mathrm{C}$ using a Soxhlet apparatus [13]. The extract was concentrated under vacuum and reduced pressure in a rotary evaporator at $45^{\circ} \mathrm{C}$. The amount of the residue so obtained was recorded.

\section{Column chromatography}

The crude ethyl acetate extract was further subjected to column chromatography using silica gel mesh (120-size) as adsorbent. Elution was done by hexane:ethyl acetate $(3: 1,1: 1$, and $3: 1)$ mixture. The fractions were collected in $50 \mathrm{ml}$ beakers. Each of these fractions was evaporated to dryness.

\section{Analytical thin-layer chromatography (TLC)}

Analytical TLC was done using Silica gel 60 F 254 plates (Merck, Germany). The fractions obtained from column chromatography were dissolved in acetone and spotted on the TLC plates. The plates were developed using the solvent system toluene:ethyl acetate (9:1). The retention factor $\left(\mathrm{R}_{\mathrm{f}}\right)$ value was calculated.

$$
\text { Retention Factor }\left(\mathrm{R}_{\mathrm{f}}\right)=\frac{\text { Distance travelled by the solute front }}{\text { Distance travelled by the solvent front }}
$$

\section{Preparative TLC}

The fractions which showed similar chromatograms were pooled together. When single spots were produced, corresponding to the 
$\mathrm{R}_{\mathrm{f}}$ value obtained from the analytical TLC, they were scraped out, centrifuged, and purified. Each of these steps was repeated at least 5 times.

\section{Chemical characterization of the purified compound(s)}

Physical properties

The colour, shape of crystals, and nature of solubility of the purified compound(s) in different solvents were noted. Melting point was determined using a melting point apparatus

\section{Structure determination}

The ultraviolet (UV)-visible spectrum was taken using UV-2400 PC Series Shimadzu Spectrophotometer, wavelength 200-800 nm. Fourier transform-infrared (FTIR) analysis of the isolated compound was taken in $\mathrm{KBr}$ pellets using Shimadzu IR Prestige 21, spectrophotometer. Liquid chromatography-mass spectrometry (LC-MS/MS) analysis was done using AB Sciex API 2000 System. The scanning was performed using four different "declustering potentials" (DPs) such as $40 \mathrm{~V}, 60 \mathrm{~V}, 80 \mathrm{~V}$, and $100 \mathrm{~V} .{ }^{1} \mathrm{H}$ nuclear magnetic resonance $\left({ }^{1} \mathrm{HNMR}\right)$ spectra were recorded on a Bruker $400 \mathrm{MHz}$ NMR spectrometer using deuterated acetone as the solvent. ${ }^{1} \mathrm{HNMR}$ spectra were detected at $\delta$ ppm $(0-10)$ scale with end sweep at $0 \mathrm{ppm}$. Molecular modeling was done using NWChem program, the structure and vibrational data have been generated using Density functional theory calculations. B3LYP methods were employed using $6-31+G^{*}$ basis set.

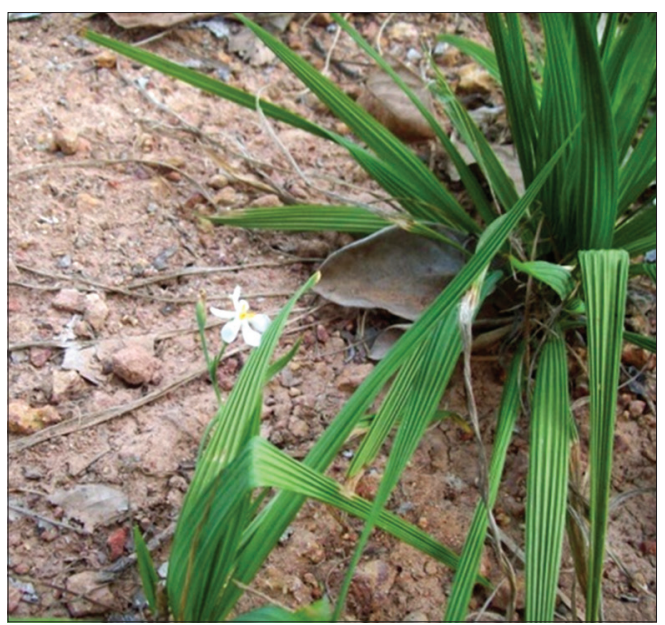

Fig. 1: Eleutherine bulbosa

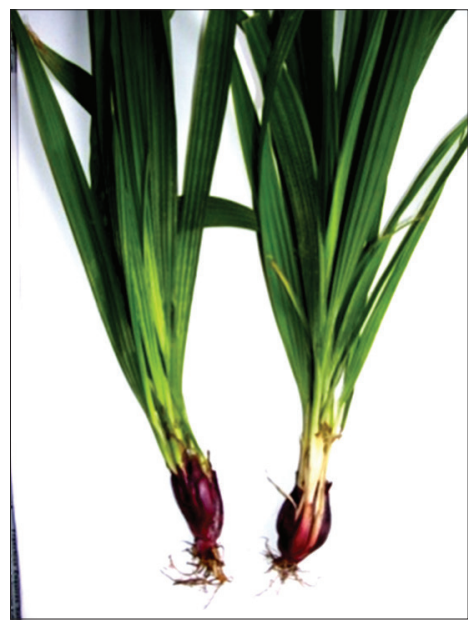

Fig. 2: Bulbs of the plant

\section{RESULTS}

\section{Extraction}

When $600 \mathrm{~g}$ of the dried bulb powder was extracted with $5 \mathrm{l}$ of ethyl acetate, the extract yield was $60 \mathrm{~g}$. This concentrated residue was subjected to column chromatography followed by TLC.

\section{Isolation and quantification of the naphthoquinone compound}

The different fractions obtained from column chromatography were collected in small glass vials. A total of about 12 fractions were obtained. The fractions obtained from column chromatography were subjected to analytical TLC. The only solvent mixture that revealed distinct bands in the analytical TLC was hexane:ethyl acetate (1:1). Three identical fractions $E$. bulbosa fraction (EBF) EBF8, EBF9, and EBF10, which eluted in hexane-ethyl acetate mixture (1:1) showed a similar pattern. These fractions were pooled together and concentrated in vacuo. The residue so obtained was an yellowish-brown crystalline compound. The crystalline compound weighed about $40 \mathrm{mg}$ and is hitherto referred to as the E. bulbosa isolated compound (EBIC).

\section{TLC analysis}

Analysis of the purified compound from E. bulbosa - EBIC by TLC (Fig. 3a and $3 b$ ) showed a single band with blue fluorescence at $R_{f}$ value 0.85 under long UV (365 nm). Under visible light, the single band showed a yellow color. The solvent system was toluene:ethyl acetate (9:1)

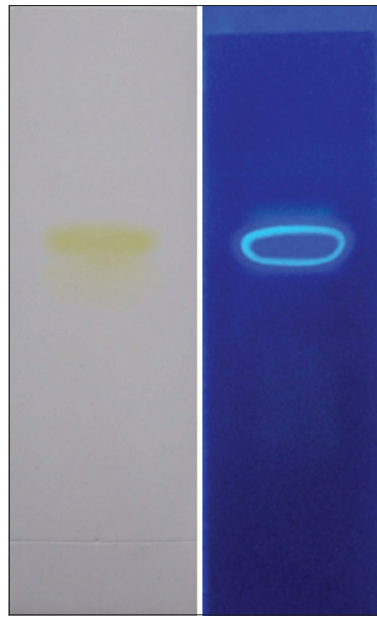

Fig. 3: (a) Thin-layer chromatography (TLC) of the purified compound from Eleutherine bulbosa under visible light. (b) TLC of the purified compound from $E$. bulbosa under long ultraviolet $(365 \mathrm{~nm})$

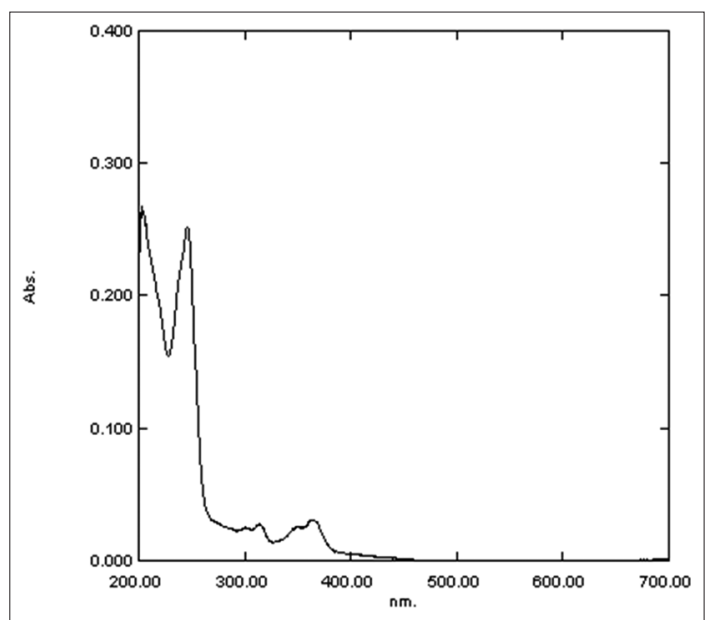

Fig. 4: Ultraviolet-visible spectrum of purified compound from Eleutherine bulbosa 
Analysis of physical properties

The isolated compound was pure with an $\mathrm{R}_{\mathrm{f}}$ value 0.85 . The compound was an yellowish-brown crystalline needle-shaped solid with a melting point $195-196^{\circ} \mathrm{C}$ at $760 \mathrm{~mm}$ of $\mathrm{Hg}$. Among the solvents (hexane, ethyl acetate, and water) tested, the compound was found to be the most soluble in ethyl acetate while it was insoluble in water.

\section{Structure elucidation}

$U V$-vis profile

The UV-vis profile of the purified compound showed peaks at 246 and $203 \mathrm{~nm}$ with absorbences, 0.251 and 0.268 , respectively (Fig. 4).

\section{FTIR analysis}

FTIR (KBr) analysis showed the following peaks: 3487, 3062, 3034, 2873, and $1641 \mathrm{~cm}^{-1}$ and it is indicated in Fig. 5 .

\section{LC-MS/MS analysis}

LC-MS/MS analysis showed the mass of the compound as $m / z 244$ $\left(\mathrm{MH}^{+}=245\right)$ and it is showed in Fig. 6 .

\section{${ }^{1}$ HNMR analysis}

${ }^{1}$ HNMR showed peaks at $9.902,7.169,7.882$, and 4.213 and between 0.9 and 1.5 ppm (Fig. 7).

From the computed (molecular modeling) and the above spectroscopic results, it is inferred that the purified compound, EBIC from E. bulbosa, in all probability is a naphthoquinone derivative with amino, carbonyl, and methyl substituents. The name of the compound was identified as bis (2-6,7-diamino-5,8-dioxo naphthalene-1yl) propanal after comparison with chemical databases such as Guidechem Chemical Network and Chemical Manufacturers Dictionary. From the results of the different spectroscopic analyses and information from chemical databases, the chemical structure of the compound is as given in Fig. 8.

\section{DISCUSSION}

The UV-vis spectroscopy of the isolated pure compound showed that it was a naphthoquinone. Naphthoquinones are known to show UV absorption at a range between $200 \mathrm{~nm}$ and $300 \mathrm{~nm}$ [14]. The UVvis profile of the compound showed peaks at $246 \mathrm{~nm}$ and $203 \mathrm{~nm}$. The results of FT-IR indicated the possibility of aromatic (phenolic) compound with substituted amino and aldehyde groups. The FT-IR showed peaks at 3062.96 and $3034.03 \mathrm{~cm}^{-1}$ indicating the presence of aromatic ring structure, peaks at $1641 \mathrm{~cm}^{-1}$ and $3487.3 \mathrm{~cm}^{-1}$ indicating the presence of amino group, and peaks at $2873 \mathrm{~cm}^{-1}$ indicating the presence of $-\mathrm{CH}_{3}$ group [15]. The mass of the compound from LCMS MS spectra at different DPs was $m / z$ 244. Based on the spectra, the molecular formula assigned to the compound was $\mathrm{C}_{13} \mathrm{H}_{12} \mathrm{~N}_{2} \mathrm{O}_{3}$. The spectral peak between $7.169 \mathrm{ppm}$ and $7.882 \mathrm{ppm}$ indicated the presence of hydrogen in the aromatic compound, a peak at $9.902 \mathrm{ppm}$ indicated the presence of hydrogen in the aldehyde (- $\mathrm{CHO}$ ) group, between 0.9 and $1.5 \mathrm{ppm}$ indicated the $\mathrm{CH}_{3}$ group, and a peak at $4.213 \mathrm{ppm}$ indicated hydrogen in amino group $\left(\mathrm{RNH}_{2}\right)$.

The ${ }^{1}$ HNMR study was helpful in the structural interpretation of the compound. A literature review showed that several naphthoquinones

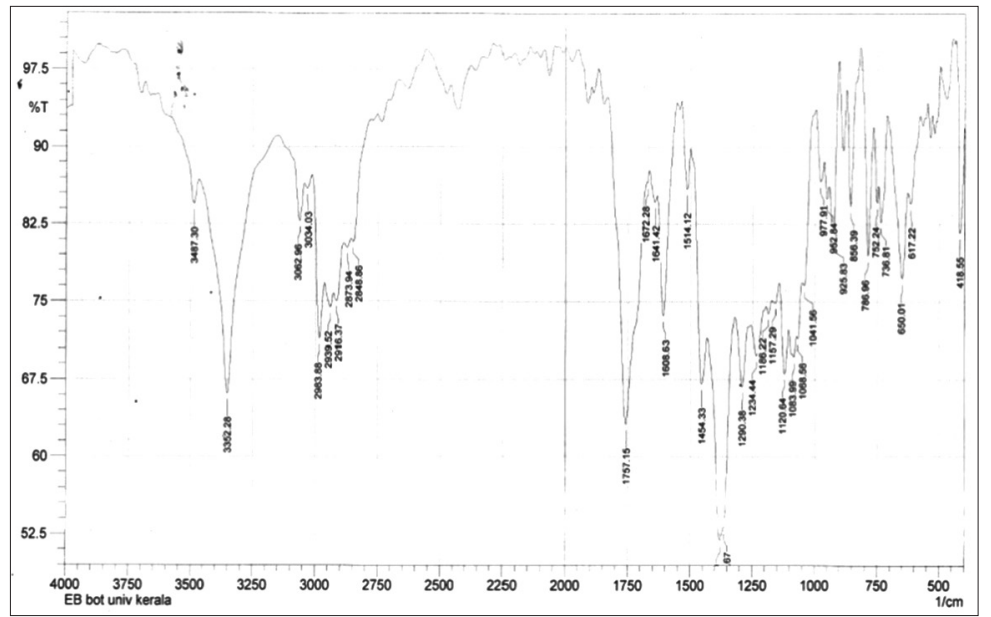

Fig. 5: Fourier transform-infrared spectrum of purified compound from Eleutherine bulbosa

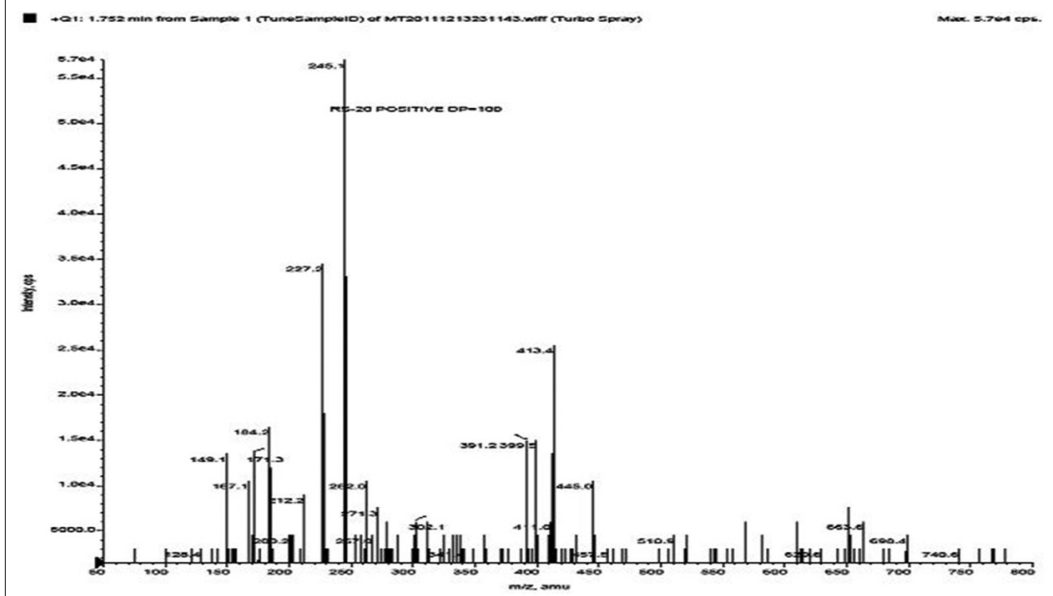

Fig.6: Liquid chromatography-mass spectrometry spectrum of the purified compound from Eleutherine bulbosa 


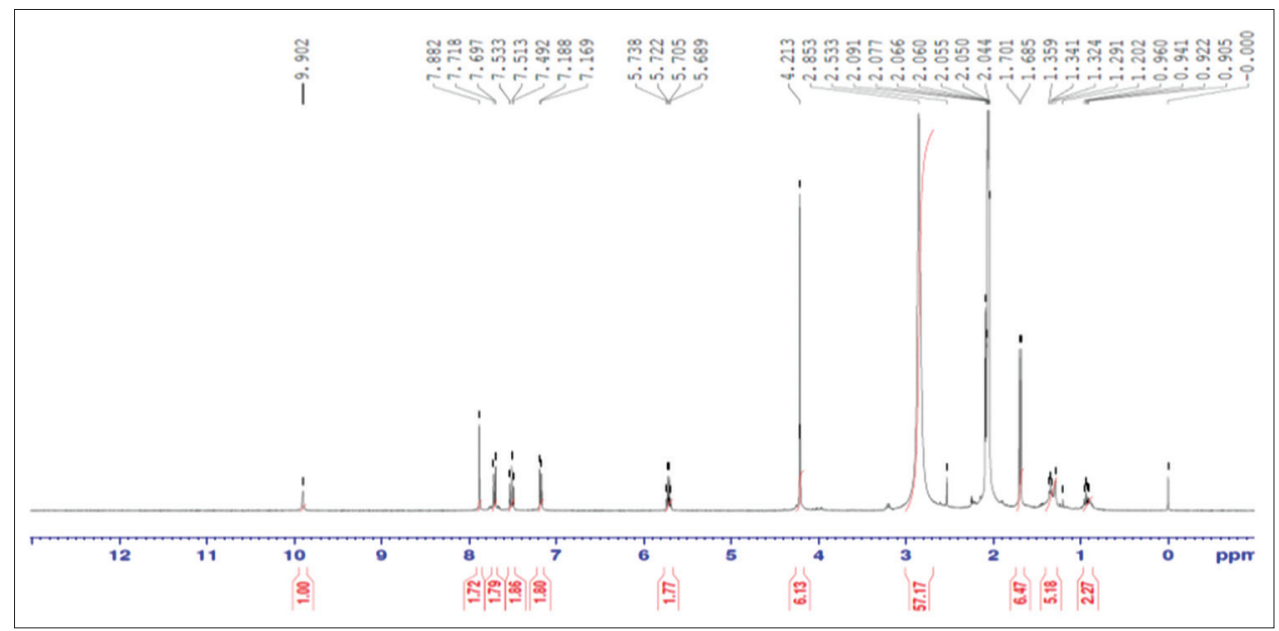

Fig. 7: ${ }^{1} \mathrm{H}$ nuclear magnetic resonance spectrum of purified compound from Eleutherine bulbosa

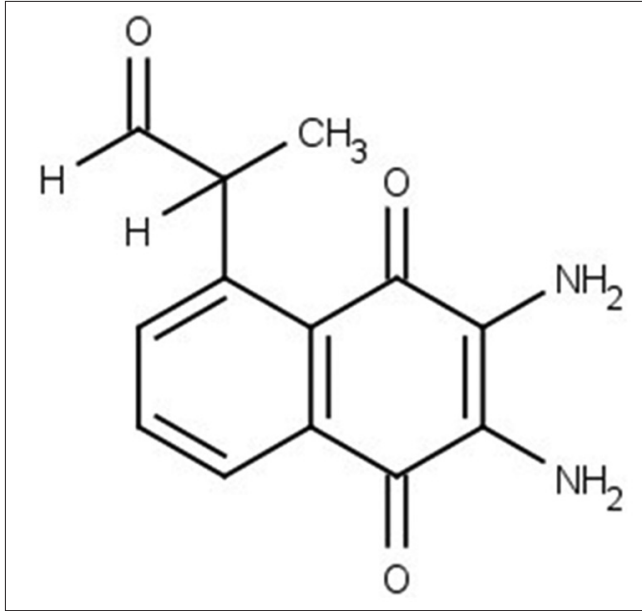

Fig. 8: Structure of the purified compound isolated from Eleutherine bulbosa [bis (2-6, 7-diamino-5, 8-dioxo naphthalene1yl) propanal]

and their derivatives exhibit ${ }^{1} \mathrm{HNMR}$ peaks between 7.169 and $7.882 \mathrm{ppm}$ [16]. Earlier, a naphthoquinone, 11-hydroxyeleutherin isolated from the related genus, Cipura paludosa (Iridaceae) showed ${ }^{1} \mathrm{HNMR}$ peaks at $7.31 \mathrm{ppm}, 7.68 \mathrm{ppm}$, and $7.74 \mathrm{ppm}$ indicating the presence of hydrogen's in the naphthoquinone skeleton [17]. It could be interpreted from the above spectroscopic results that the compound, EBIC is a naphthoquinone derivative with amino, carbonyl, and methyl substituent.

The spectral characteristic interpretations are useful in the structural elucidation of bioactive compounds from plant extracts [18-20]. A few bioactive naphthoquinones and their derivatives have been isolated from the bulbs of E. bulbosa. A fungitoxic naphthoquinone, eleutherinone [21], polyketides such as eleutherin [22], and eleuthoside having $\alpha$-glucosidase inhibitory activity [23] were isolated from this plant. The present study reports for the $1^{\text {st }}$ time the presence of a novel naphthoquinone derivative from the bulbs of E. bulbosa.

\section{CONCLUSION}

An yellowish-brown crystalline needle-shaped compound was isolated from the bulbs of E. bulbosa and characterized chemically. Spectroscopic analysis identified the compound as bis (2-6,7-diamino-5,8-dioxo naphthalene-1yl) propanal.

\section{ACKNOWLEDGMENTS}

The author is grateful to Dr. Bindu R Nair, Assistant Professor, Department of Botany, University of Kerala, for proper guidance and support. I am also grateful toward Dr.PM Radhamany, Former Head, Department of Botany, University of Kerala, Thiruvananthapuram, Kerala, for guidance and encouragement. The service provided by the Department of Chemistry, Government College for Women, Thiruvananthapuram for FTIR analysis, IIRBS, Kottayam, Kerala, for ${ }^{1}$ HNMR analysis and Interfield Laboratories for LC-MS/MS analysis are also acknowledged here.

\section{CONFLICTS OF INTEREST}

The author has no conflicts of interest.

\section{REFERENCES}

1. Quisumbing E. Medicinal Plants of the Philippines. Manila: Philippines Department of Agricultural and Natural Resources Technical Bulletin; 1951.p. 1234.

2. Goldblatt P, Snow N. Systematics and Chromosome cytology of Eleutherine Herbert (Iridaceae). Ann Mol Bot Gard 1991;78:942-9.

3. Panda SK, Patra N, Sahoo G, Bastia AK, Dutta SK. Anti-diarrhoeal activities of medicinal plants in Similipal Biosphere, Odisha, India. Int J Med Arom Plants 2012;2:123-34.

4. Kuriachan PI, Cherian M. A Preliminary Study of the Cytotoxic Effects of the Medicinal Plant Eleutherine bulbosa using Allium cepa Root Tip Meristem. Proceedings of the Kerala Science Congress; 1989.

5. Hasimun P, Zakaria H, Susilawati E, Wardiono JD. Antihypertensive activity ethanolic extract of bulb Eleutherine american merr on fructose-induced hypertension rats. Int J Pharm Pharm Sci 2017;9:25-8.

6. Rani VS, Bindu RN. Antimicrobial effects of crude extracts of Eleutherine bulbosa. J Med Arom Plant Sci 2011;33:46-52.

7. Rani VS, Bindu RN. In vitro Cytotoxic Activity of the Medicinal Plant Eleutherine bulbosa (Miller) Urban against Dalton's Lymphoma Ascitic Cell Lines. Aluva, Ernakulam, Kerala: Proceedings of the National Conference on Genes and Genome Research in India held at Department of Botany, Union Christian College; 2011.

8. Brasileiro BG, Pissiolo RP, Raslan DS, Jamal M, Silveira D. Antimicrobial and cytotoxic activities screening of some Brazilian medicinal plants used in Governador Valadares district. Braz J Pharm Sci 2006;42:195-202.

9. Lans C. Ethnomedicines used in Trinidad and Tobago for reproductive problems. J Ethnobiol Ethnomed 2007;3:1-13.

10. Hara H, Maruyama N, Yamashita S, Hayashi Y, Lee KH, Bastow KF, et al. Elecanacin, a novel new naphthaquinone from the bulb of Eleutherine Americana. Chem Pharm Bull 1997;45:1714-6.

11. Nielsen LB, Wege D. The enantioselective synthesis of elecanacin through an intramolecular naphthoquinone-vinyl ether photochemical cycloaddition. Org Biomol Chem 2006;4:868-76.

12. Ha LM, Huyen DT, Kiem PV, Minh CV, Van NT, Nhiem NX, et al. 
Chemical constituents of the rhizome of Eleutherine bulbosa and their inhibitory effect on the pro-inflammatory cytokines production in lipopolysaccharide-stimulated bone marrow-derived dendritic cells. Bull Korean Chem Soc 2013;33:633-6.

13. Harborne JB. Phytochemical Methods: A Guide to Modern Techniques of Plant Analysis. $3^{\text {rd }}$ ed. London: Chapman and Hall Ltd; 1998. p. 4-7.

14. Thomson RH. Naturally Occurring Quinones. London, New York: Academic Press Inc. Ltd; 1971. p. 64.

15. Coates J. Interpretation of infrared spectra, a practical approach. In: Meyers RA, editor. Encyclopedia of Analytical Chemistry. Chichester: John Wiley and Sons Private Ltd; 2000. p. 1-23.

16. Higa $M$, Noha $N$, Yokaryo H, Ogihara K, Yogi S. Three new naphthoquinone derivatives from Diospyros maritima Blume. Chem Pharm Bull 2002;50:590-3

17. Tessele PB, Monache FD, Quintão NL, da Silva GF, Rocha LW, Lucena GM, et al. A new naphthoquinone isolated from the bulbs of Cipura paludosa and Pharmacological Activity of Two Main Constituents. Planta Med 2011;77:1035-43.

18. Ghai R, Nagarajan K, Gupta N, Isolation and characterization of a novel chemical compound from Eugenia caryophyllus flower bud extract. Int J Pharm Sci 2014;6:531-6.

19. Khan AM, Bhadauria S. Isolation of some potential phytocompounds from Adhatoda vasica through Gas chromatotography-Mass spectroscopic analysis. Asian J Pharm Clin Res 2017;10:328-32.

20. Goudar MA, Jayadevappa H, Mahadevan KM, Shastry RA, Habbu PV, Sayeswara HA. Isolation and characterization of secondary metabolite from Habernaria intermedia D Don for screening of hepatoprotective potential against carbon tetrachloride induced toxicity in albino rat liver. Int J Curr Phar Res 2015;7:57-61.

21. Alves TM, Kloos H, Zani CL. Eleutherinone, a novel fungitoxic naphthaquinone from Eleutherine bulbosa (Iridaceae). Mem Inst Oswald Cruz 2003;98:709-12.

22. KusumaI W, Arung ET, Rosamah E, Purwatiningsih S, Kuspradini H, Astuti J, et al. Antidermatophyte and antimelanogenesis compound from Eleutherine americana grown in Indonesia. J Nat Med 2010;64:223-6.

23. Ieyama T, Maria DP, Puteri G, Kawabata J. $\alpha$-Glucosidase inhibitors from the bulbs of Eleutherine americana. Food Chem 2011;128:308- 11. 